\title{
Compliance, Hysteresis, and Collapsibility of Human Small Airways
}

\author{
HARM A. W. M. TIDDENS, WARD HOFHUIS, JAN M. BOGAARD, WIM C. J. HOP, HUIB de BRUIN, \\ LUC N. A. WILLEMS, and JOHAN C. de JONGSTE
}

Department of Pediatrics, Division of Respiratory Medicine, Department of Biostatistics, Department of Pathology, Sophia Children's Hospital, Erasmus Medical Center Rotterdam, Rotterdam; and Department of Pulmonary Medicine, Leiden University Medical Center, Leiden, The Netherlands

\begin{abstract}
We tested the hypothesis that airway wall dimensions are important determinants for the mechanical properties of airways. Lung tissue was obtained from 31 smokers with different degrees of chronic obstructive pulmonary disease (COPD) who were operated on for a solitary lung lesion. Segments of small airways $(n=35)$ were mounted on cannulas in an organ bath and inflated and deflated cyclically between +15 and $-15 \mathrm{~cm} \mathrm{H}_{2} \mathrm{O}$. For each airway this was done at baseline, after methacholine, and after isoprenaline. Specific compliance ( $s \mathrm{Cdyn}$ ), specific hysteresis $(\mathrm{s} \eta)$, and pressure at which the airways collapsed (Pcol) were calculated from each recording. Airway wall dimensions were measured morphometrically. Lung function parameters of airflow obstruction were correlated to $\mathrm{sCdyn}, \mathrm{s} \eta$, and Pcol. At baseline, after methacholine, and after isoprenaline $\mathrm{sCdyn}$ was 0.059 , 0.052 , and $0.085 \mathrm{~cm} \mathrm{H}_{2} \mathrm{O}^{-1}, \mathrm{~s} \eta$ was $13.5,12.9$, and $7.1 \%$, and Pcol was $-3.4,-3.5$, and $-1.9 \mathrm{~cm} \mathrm{H}_{2} \mathrm{O}$, respectively. Differences between $\mathrm{sCdyn}, \mathrm{s} \eta$, and Pcol after methacholine and after isoprenaline were highly significant $(p<0.001)$. Of all dimensions studied, smooth muscle area, but not total wall area, was the most important determinant for $\mathrm{sCdyn}$ and for $\mathrm{s} \eta$ after methacholine. Specific hysteresis at baseline correlated to residual volume as a fraction of total lung capacity (RV/TLC) $(r=0.5, p=$ $0.05)$ and, in the presence of methacholine, to $\mathrm{FEV}_{1} / \mathrm{FVC}(r=-0.68, p=0.02)$ and $\mathrm{RV} / \mathrm{TLC}(r=0.5$, $p=0.05$ ). We conclude that, in this study, smooth muscle area and smooth muscle tone, but not total wall area, are determinants for compliance, hysteresis, and collapsibility of isolated airways obtained from smokers. Tiddens HAWM, Hofhuis W, Bogaard JM, Hop WCJ, de Bruin H, Willems LNA, de Jongste JC. Compliance, hysteresis, and collapsibility of human small airways.
\end{abstract}

AM J RESPIR CRIT CARE MED 1999;160:1110-1118.

In chronic obstructive pulmonary disease (COPD) airway inflammation is associated with increased airway wall thickness (1). This thickness is relatively more severe in peripheral airways than in central airways, and is more pronounced in patients with more severe airflow obstruction (1). Similar findings were obtained in patients who died with or from asthma $(2,3)$. Thickening of the airway wall as such has little effect on airway resistance (1). H owever, in combination with smooth muscle shortening it causes an important increase of airway resistance $(4,5)$. The extent to which the smooth muscle in airways of patients with COPD shortens will depend on the force it develops and on the load against which the smooth muscle has to contract. Increased smooth muscle force in COPD has been described by some investigators (6) but not by others (7). I sotonic shortening was decreased in airway muscle from patients with COPD compared with smokers without airflow ob-

(Received in original form September 2, 1997 and in revised form December 15, 1998) Supported by research grants from the Dutch Asthma Fund (NAF 91.08).

Correspondence and requests for reprints should be addressed to H. A. W. M. Tiddens, Sophia Children's Hospital, Dr. Molewaterplein 60, 3015 GJ Rotterdam, The Netherlands. E-mail: tiddens@alkg.azr.nl

Am J Respir Crit Care Med Vol 160. pp 1110-1118, 1999

Internet address: www.atsjournals.org struction (8). These findings suggest that in COPD the load on the bronchial smooth muscle might be increased. In fact, chronic airway inflammation is associated with deposition of fibrous tissue such as collagen and elastin within different compartments of the airway wall (9-13). This probably makes airways stiffer (i.e., less compliant) and increases the load against which the smooth muscle contracts. We hypothesize that airway wall thickness is an important determinant of the mechanical properties of airways and that reduced compliance makes the airways less collapsible and decreases their distensibility and hysteresis.

This study was undertaken to evaluate the relation between compliance, collapsibility, and hysteresis, on the one hand, and wall dimensions of human peripheral airway segments on the other hand. Therefore, we have developed an experimental model to study compliance, hysteresis, and collapsibility of isolated human small airway segments at baseline tone and after maximal contraction and relaxation of the airway smooth muscle.

\section{METHODS}

Study Population

L ung tissue was obtained from 31 patients who had a lobar resection or pneumonectomy for a peripheral lung lesion. These patients were 
mostly smokers and were classified as "COPD" although one-third had a lung function within the normal range and, therefore, did not strictly fulfil the A merican Thoracic Society criteria (14). Preoperative routine lung function was obtained from 27 of 31 patients. Forced expiratory volume in one second $\left(F E V_{1}\right)$, forced vital capacity $(F V C)$, maximal flows at $50 \%\left(\dot{V}_{\max }\right)$ and $25 \%\left(\dot{V} \max _{25}\right)$ of $\mathrm{FVC}$, functional residual capacity $(F R C)$, total lung capacity $(T L C)$, residual volume ( $R V$ ), and $R V$ as a fraction of TLC ( $R V / T L C \%$ pred) are all expressed as percentage of predicted (15). We used $F E V_{1}$, expressed as a percentage of $F V C\left(F E V_{1} / F V C\right)$, as an indicator of the severity of airflow obstruction. Reversibility of bronchial obstruction was expressed as the absolute change in $\mathrm{FEV}_{1}$ as a percentage of the predicted $\mathrm{FEV}_{1}\left(\Delta \mathrm{FEV} \mathrm{V}_{1} \%\right.$ pred) and as a percentage of the actual prebronchodilator $\mathrm{FEV}_{1}\left(\Delta \mathrm{FEV}_{1} \%\right.$ ini). This protocol was approved by the institutional review board for human studies.

\section{Airway Segments}

Lung tissue was collected and transported on ice in carbogenated $\left(5 \% \mathrm{CO}_{2}, 95 \% \mathrm{O}_{2}\right) \mathrm{K}$ rebs- $\mathrm{H}$ enseleit buffer (composition in $\mathrm{mM} \mathrm{:} \mathrm{N} \mathrm{aCl}$ $118, \mathrm{~K} \mathrm{Cl} 4.7, \mathrm{CaCl}_{2} 2.5, \mathrm{M} \mathrm{gSO}_{4} 1.2, \mathrm{KH}_{2} \mathrm{PO}_{4} 1.2, \mathrm{NaH} \mathrm{CO}_{3} 25$, glucose 5.55). Peripheral airways were identified, cannulated with a thin plastic cannula, and dissected out with surrounding parenchyma. The airways were stored overnight in carbogenated $\mathrm{K}$ rebs-H enseleit buffer at $4^{\circ} \mathrm{C}$. N ext morning, parenchyma and blood vessels were removed with the help of a dissection microscope (Stemi 2000; Carl Zeiss, $O$ berkochen, G ermany) and all side branches identified and ligated in a watertight fashion. A irway segments at least $5 \mathrm{~mm}$ in length were selected for in vitro measurements. The internal diameters of the endings of the airways were estimated using the microscope by selecting stainless steel cannulas $(1,1.5,2,3$, or $4 \mathrm{~mm})$ that most closely fitted the diameter of the airway. N ext, the airways were mounted in the organ bath on the cannulas in a watertight fashion. The airways were perfused to test for patency and possible leaks. The length of the unstretched airway within the inner borders of the cannula sutures was measured by a digital calipers (precision $0.1 \mathrm{~mm}$ ). N ext, we stretched the airway to $140 \%$ of this length, that being the estimated length of an airway close to TLC (16). A t this length the airway remained patent at low transmural pressures and after contraction by methacholine. The volume $(\mu \mathrm{l})$ of the airway was estimated by the formula $\pi r^{2}$ l, where $r$ is the average of the radius $(\mathrm{mm})$ of the two cannulas and $I$ is the length $(\mathrm{mm})$ of the stretched airway.

\section{Description of Experimental Setup}

Figure 1 shows the experimental setup we used to measure the dynamic properties of the airway segments. It consists of a double-jacketed organ bath in which the cannulated airway segment was mounted. The organ bath is filled with $\mathrm{K}$ rebs-Henseleit buffer at a temperature of $37^{\circ} \mathrm{C}$ and continuously gassed with carbogen. A irway segment and tubing are filled with buffer. A II connecting tubing has a low compliance. Pressure was measured at both ends of the airway segment $\left(\mathrm{P}_{\text {prox }}\right.$ and $\left.\mathrm{P}_{\text {dist }}\right)$ using pressure transducers with a low compliance ( $143 \mathrm{PC} \pm 1 \mathrm{psi} ; \mathrm{M}$ icro Switch, F reeport, IL). The compliance of the whole system was $0.03 \mu \mathrm{l} \mathrm{cm} \mathrm{H}_{2} \mathrm{O}^{-1}$. B y means of a 3-way valve, the airway segment can be connected to a gas-tight syringe mounted on a computer-controlled, high-precision syringe pump ( $\mathrm{H}$ arvard 22; $\mathrm{H}$ arvard A pparatus Inc., South Natick, M A ) for cyclic inflation and deflation. Furthermore, the segment can be connected to a microplethysmograph that was designed to measure small volume displacements from or to the airway under isobaric conditions. Finally, the segment can be connected to a reservoir filled with buffer for perfusion. The transmural pressure signals $\left(P_{\text {prox }}\right.$ and $\left.P_{\text {dist }}\right)$, the volume signal of the syringe pump, and the volume signal of the microplethysmograph $\left(P_{\text {diff }}\right)$ are all displayed on the computer monitor. The system is servo-controlled, with the pressure signal from $\mathrm{P}_{\text {prox }}$ being used to control the syringe pump.

\section{Measurement Protocol}

The $\mathrm{K}$ rebs buffer in the organ bath was replaced every $15 \mathrm{~min}$ throughout the experiments. B etween tests the airway was perfused for $10 \mathrm{~min}$. The speed of the pump for inflation and deflation was set

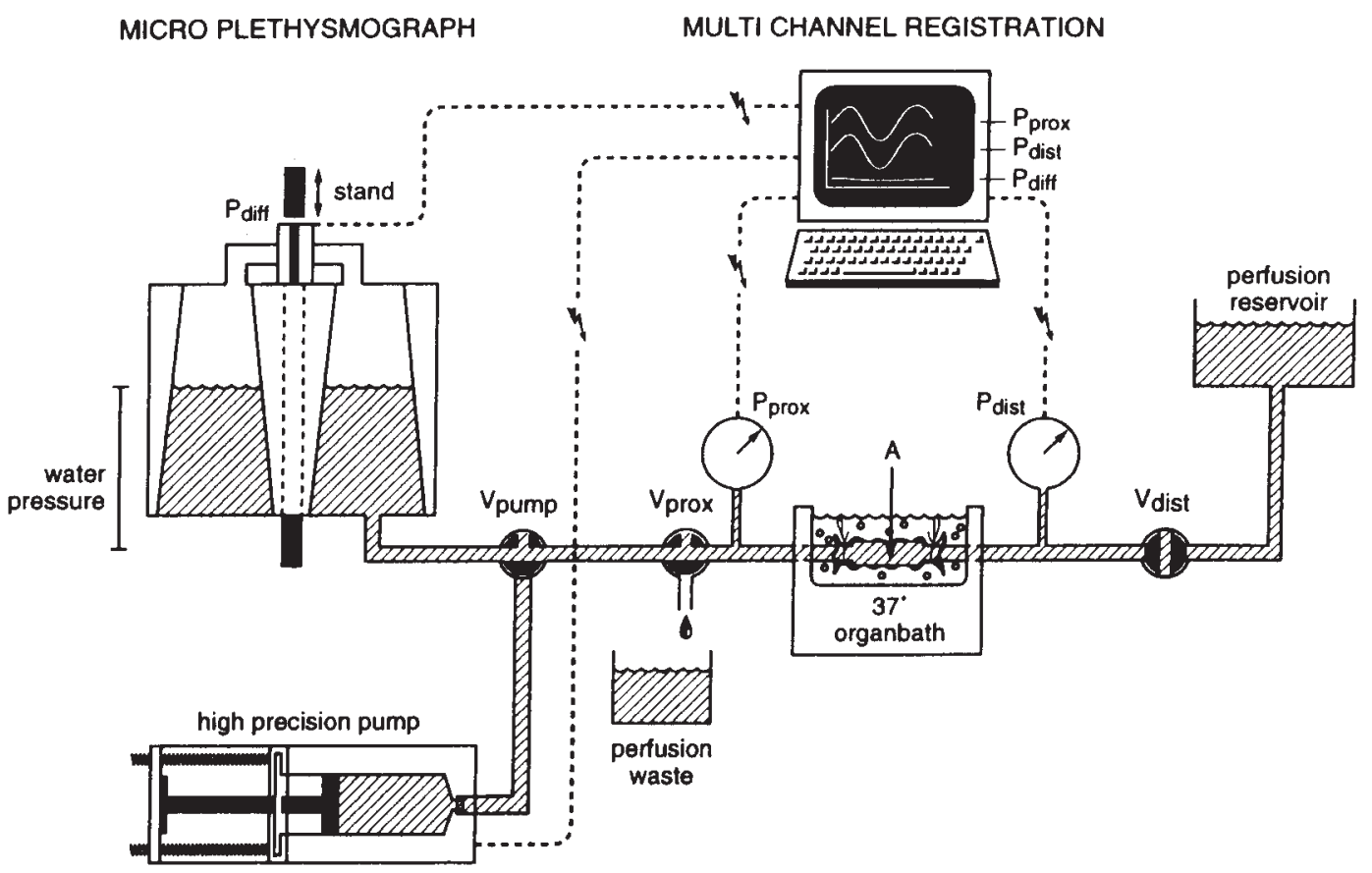

Figure 1. Diagram of the experimental setup to measure dynamic properties of isolated airway segments. $\mathrm{A}=$ cannulated airway; $\mathrm{V}_{\text {prox }}$ and $\mathrm{V}_{\text {dist }}=$ valves located at the proximal or distal end of the airway; $\mathrm{V}_{\text {pump }}=$ valve to connect pump to airway; $\mathrm{P}_{\text {prox }}$ and $\mathrm{P}_{\text {dist }}=$ pressure transducers to measure the transmural pressure at the proximal and distal ends of the airway; microplethysmograph = device to measure small volume displacements under isobaric conditions; multichannel registration = system for processing of pressure and volume signals; high-precision pump = pump for cyclic inflation and deflation of airway. The system is servo-controlled, with the pressure signal from $\mathrm{P}_{\text {prox }}$ controlling the syringe pump. 
at 8 times the estimated volume of the airway segment per minute. From a pilot study, we estimated that this would give a cycling rate between 1 and 4 cycles per minute.

L eak test. To test for a leak, the airway was inflated by the pump until a transmural pressure of $15 \mathrm{~cm} \mathrm{H}_{2} \mathrm{O}$ was obtained. $\mathrm{N}$ ext, the spontaneous rate of pressure drop of the segment within the first minute of inflation was recorded. In case of leakage it was either impossible to inflate the airway to $15 \mathrm{~cm} \mathrm{H}_{2} \mathrm{O}$, or its transmural pressure dropped rapidly to $0 \mathrm{~cm} \mathrm{H}_{2} \mathrm{O}$ after inflation stopped.

Pressure-volume relation at baseline. Z ero pressure of the proximal and distal valves was set by connecting the airway lumen to the atmosphere. The airway was then connected to the pump. $\mathrm{N}$ ext, the airway was cyclically inflated and deflated between +15 and $-15 \mathrm{~cm}$ $\mathrm{H}_{2} \mathrm{O}$ using the computerized servo-controlled pump (Figure 2). The upper pressure limit of $15 \mathrm{~cm} \mathrm{H}_{2} \mathrm{O}$ was chosen because it corresponds to the plateau of the pressure-volume curve of an air-filled system (17). This transmural pressure is, therefore, likely to inflate the airway to a level comparable to TLC. Three complete inflation-deflation cycles were done. A fter the third cycle, the airway was inflated to $15 \mathrm{~cm}$ $\mathrm{H}_{2} \mathrm{O}$ at which point the pump automatically stopped. We recorded the spontaneous pressure drop within 2 min to estimate maximal hysteresis and leak.

I sobaric contractility and relaxation. To monitor the contractile response to methacholine or relaxation response to isoprenaline the airway was connected to the microplethysmograph. The transmural pressure was set at $10 \mathrm{~cm} \mathrm{H}_{2} \mathrm{O}$ by adjusting the height of the plethysmograph. B aseline volume displacement out of the plethysmograph was recorded for 2 min before sufficient methacholine or isoprenaline was added to the organ bath to give a final concentration of $10^{-4} \mathrm{M}$. The isobaric constriction or relaxation was recorded until no more fluid was displaced into the plethysmograph or until the rate of fluid displacement out of the plethysmograph became constant.

Pressure-volume relation in the presence of methacholine and isoprenaline. These were measured as described for baseline tone.

I sobaric relaxation. To monitor the relaxation response to isoprenaline the airway was connected to the microplethysmograph. The transmural pressure was set at $10 \mathrm{~cm} \mathrm{H}_{2} \mathrm{O}$ by adjusting the height of the plethysmograph. B aseline volume displacement out of the plethysmograph was recorded for 2 min before isoprenaline $\left(10^{-4} \mathrm{M}\right)$ was added to the organ bath. The isobaric relaxation was recorded until the rate of fluid displacement out of the plethysmograph became constant.

Pressure-volume relation after isoprenaline. This was measured as described for baseline.

Fixation. F inally, the airway was perfused with formalin (10\%) from the distal end at a driving pressure of $10 \mathrm{~cm} \mathrm{H}_{2} \mathrm{O}$. The valve was closed as soon as formalin came out of the proximal valve and the $\mathrm{K}$ rebs buffer in the organ bath was quickly replaced with formalin. A fter fixation for $12 \mathrm{~h}$ at a transmural pressure of $10 \mathrm{~cm} \mathrm{H}_{2} \mathrm{O}$, the airway, in- cluding the ligatures at both ends, was gently pushed off the cannulas with forceps and stored in formalin until being processed for histology.

\section{Compliance, Hysteresis, Collapsibility, and Contractility}

Compliance ( $\mathrm{C}$ dyn, $\mu \mathrm{l} \mathrm{cm} \mathrm{H}_{2} \mathrm{O}^{-1}$ ) was calculated from the volume infused to inflate the airway from 0 to $15 \mathrm{~cm} \mathrm{H}_{2} \mathrm{O}$ (Figure 2). The transition point of the pressure-volume curve where inflation changes to deflation was selected as the upper pressure limit for the $\mathrm{C}$ dyn calculation because it is least affected by hysteresis. Furthermore, it results in the Cdyn of the stretched airway close to TLC where collagen is likely to be an important mechanical determinant $(18,19)$. Therefore, $\mathrm{C}$ dyn should be sensitive to changes in airway collagen content. H ysteresis $\left(\eta, \mu \mathrm{l} \mathrm{cm} \mathrm{H}_{2} \mathrm{O}\right.$ ) was calculated as the area of the pressure-volume loop between 0 to $15 \mathrm{~cm} \mathrm{H}_{2} \mathrm{O}$. Collapsibility ( $\mathrm{Pcol}, \mathrm{cm} \mathrm{H}_{2} \mathrm{O}$ ) was defined as the pressure of the deflation limb where the distal pressure did not follow the proximal pressure, thus indicating closure of the airway lumen. $C$ dyn, $\eta$, and Pcol were calculated for each cycle. We analyzed $C$ dyn, $\eta$, and $P$ col of the first cycle $\left(\mathrm{Cdyn}_{1}, \eta_{1}\right.$, and $\left.\mathrm{Pcol}_{1}\right)$ separately because we observed that these were always substantially different from those of the subsequent cycles. The latter were similar and were therefore taken together ( $\mathrm{Cdyn}, \eta$, and Pcol). The first cycle was excluded for analysis when it did not start exactly from $0 \mathrm{~cm} \mathrm{H}{ }_{2} \mathrm{O}$ transmural pressure. V olume loops could not be analyzed for hysteresis in 11 airways where we used a high syringe volume and low speed of the pump as this caused artifacts in the pressure-volume loops.

To normalize compliance for the volume of the airway segment, $C \mathrm{dyn}_{1}$ and $\mathrm{Cdyn}$ were divided by the volume of the airway segment as calculated by morphometry ( $\left.\mathrm{sCdyn}_{1}, \mathrm{sC} d \mathrm{yn}\right)$. H ysteresis was normalized as a percentage of the area of the maximal possible hysteresis $\left(s \eta_{1}, s \eta\right)$, which was defined as the product of volume infused and the upper pressure limit $\left(15 \mathrm{~cm} \mathrm{H}_{2} \mathrm{O}\right)$. The spontaneous pressure drop within 2 min after the last inflation was normalized for the inner surface area of the airway (internal perimeter times length) (specific

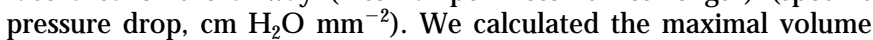
displaced by the airway segment after methacholine $\left(\mathrm{V}_{\mathrm{M}}\right)$, or isoprenaline $\left(V_{1}\right)$. The response was negative when fluid moved out of the contracting segment into the plethysmograph and positive when fluid moved into the relaxing airway segment out of the plethysmograph. The response was corrected for the rate of baseline fluid movement before methacholine or isoprenaline was added. To correct for the volume of the airway segment, $V_{M}$ and $V_{\text {, }}$ were expressed as the percentage of the volume of the airway segment as calculated from morphometry.

\section{Airway Dimensions}

To estimate airway wall dimensions and volume of the lumen, the segment was cut in cross section at both ends just inside the ligatures,
EXAMPLE OF TRACING

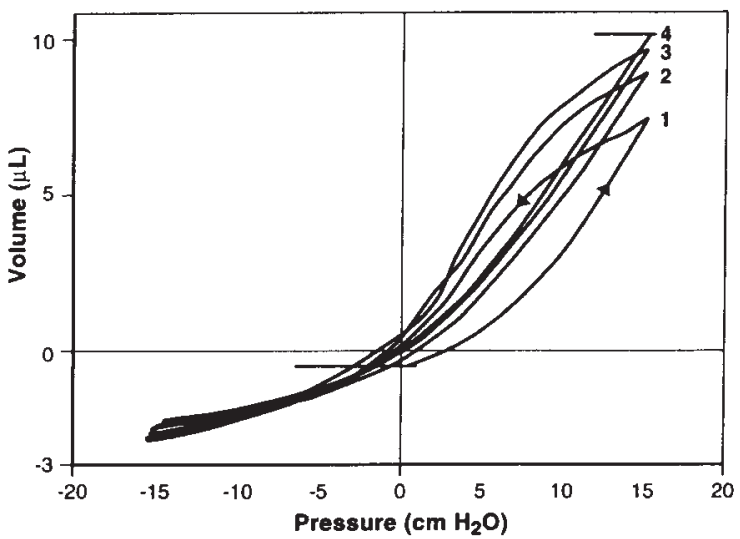

SPECIFIC HYSTERESIS

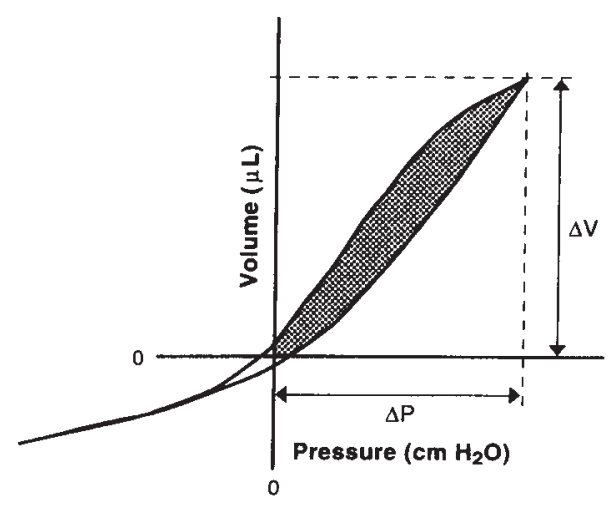

Figure 2. Example of pressure-volume tracing. The arrowhead shows the direction of the loop. Dynamic compliance (Cdyn) is the division of infused volume by $15 \mathrm{~cm} \mathrm{H}_{2} \mathrm{O}$. Specific hysteresis is the area of the pressure-volume loop above $0 \mathrm{~cm} \mathrm{H}_{2} \mathrm{O}$ expressed as the percentage of the area of the maximal hysteresis. 
decalcified, and embedded in paraffin in such a way that the airway segment could be cut in cross-section. A random starting point was selected within the first $0.5 \mathrm{~mm}$ at one end of the airway using a randomization table. Sections of $5 \mu \mathrm{m}$ thickness were cut all the way through the airway with a microtome. Every 100th section $(0.5 \mathrm{~mm})$ was selected for morphometric analysis. We estimated that with this procedure we could obtain a reliable estimate of the mean airway wall dimensions. Sections were stained with a combined G omori trichrome and elastin stain. This stain resulted in a good color contrast between airway wall structures. The measurements made are shown in Figure 3 and include: inner perimeter $\left(P_{i}\right)$ and area of the lumen bounded by the respiratory epithelium $\left(A_{i}\right)$; basement membrane perimeter $\left(P_{b m}\right)$ and the area enclosed by this perimeter $\left(A_{b m}\right)$; the outer muscle perimeter $\left(P_{m o}\right)$ and the area enclosed by this perimeter $\left(A_{m o}\right)$; the outer perimeter $\left(P_{0}\right)$ and the area enclosed by this perimeter $\left(A_{0}\right)$; the area occupied by smooth muscle (WA $\mathrm{A}_{\mathrm{m}}$ ); and the area occupied by cartilage (WA cart).

Furthermore, we measured the height of the respiratory epithelium $\left(\mathrm{H}_{\text {epi }}\right)$ and the fraction of the $\mathrm{P}_{\mathrm{bm}}$ covered by epithelium $\left(\mathrm{F}_{\mathrm{epi}}\right)$. $\mathrm{H}_{\text {epi }}$ was measured as follows. First, a grid containing parallel sinusoids was superimposed over the computer image of the airway. When respiratory epithelium was present at the point where the sinusoid crossed the basement membrane, we measured the epithelial height by drawing a straight line perpendicular from the membrane to the top of the ciliary border. The length of this line was automatically computed. When respiratory epithelium was absent, a zero was scored for height. Second, $\mathrm{H}_{\text {epi }}$ was calculated for each airway section by computing the average of at least 15 epithelial height measurements around the lumen. $\mathrm{F}_{\mathrm{epi}}$ was calculated by dividing the number of intersecting points through the basement membrane covered by respiratory epithelium with the total number of intersecting points, including the intersecting points at sites where the respiratory epithelium was absent. W $A_{\text {epi }}$ was calculated by multiplying $\mathrm{P}_{\text {bm }}$ by $\mathrm{H}_{\text {epi }}$.

From these measurements we calculated the inner wall area including epithelium ( $\left.W A_{i}=A_{m o}-A_{i}\right)$, inner wall area excluding epithelium ( $W A_{b m}=A_{m o}-A_{b m}$ ), outer wall area (WA $A_{0}=A_{0}-A_{m o}$ ), and the total wall area $\left(W A_{\text {tot }}=A_{0}-A_{i}\right)$. This nomenclature was proposed for quantifying subdivisions in the bronchial wall (20).

A irway dimensions were measured using an automated image analysis system (K S 400; K ontron E lectronic, Eching/M unich, G ermany). M easurements of airway dimensions were performed by two observers (W.H. and H.d.B.). E ach observer measured a different set of airway dimensions for all airways. The interobserver variability was assessed to compare airway dimensions of this study with a previous study in which we studied patients with variable degrees of airway wall thickening (1). This would give us evidence as to whether the patients we included in the present study had airway wall thickening in the same range as in previous studies. B oth observers remeasured 15 randomly selected airways that were measured by the observer (H.T.)

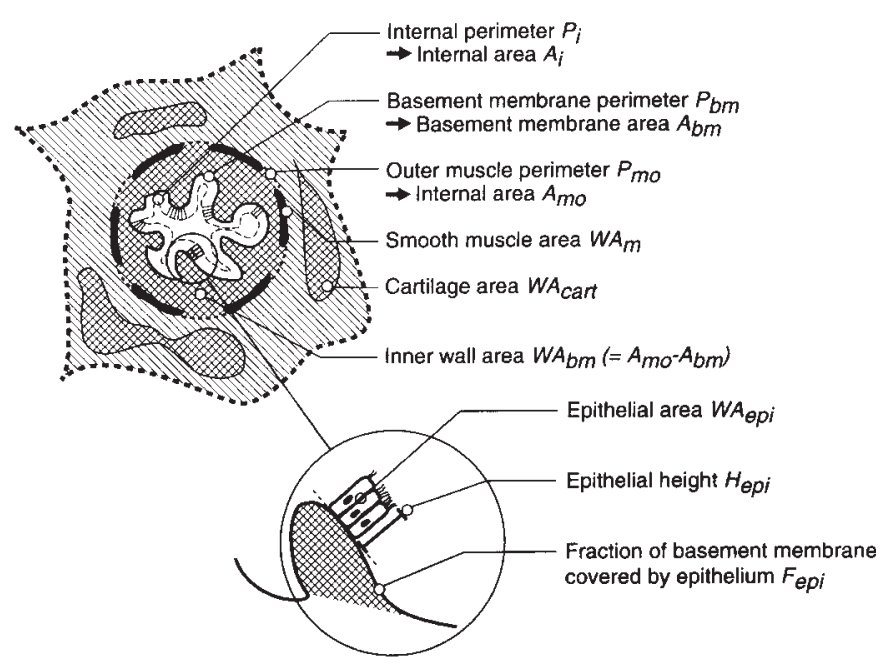

Figure 3. Diagram of measured airway dimensions. of the previous study. The intraobserver variability was assessed by remeasurement of 10 randomly selected airways with an interval of 2 mo.

Inflammatory changes of membranous airways were graded using the pictorial grading method of Wright and coworkers (21). The following indices were graded in the membranous bronchioles: inflammation, fibrosis, muscle hypertrophy, pigment deposition, goblet cell metaplasia, and squamous cell metaplasia. For each airway these six morphological indices were compared with pictorial reference standards with a score from 0 (normal) to 3 (most abnormal). Next the mean score for each morphological index for each individual specimen was calculated by summing the scores of the airways examined, divided by the number of airways examined. The average score for that variable was expressed as a percentage of maximal possible score. A total membranous airways disease score for each specimen was then calculated by summing the mean scores of the six morphological indices (maximal score: $6 \times 100=600$ ).

\section{Statistical Analysis}

The interobserver and intraobserver variability were calculated by expressing the difference of the first and the second measurement as a percentage of the average of both observations. This percentage was plotted against $P_{b m}$ to detect systematic errors dependent upon airway size (22). For each airway and each airway wall dimension, we calculated the average and the standard error of the mean (SE M ). To estimate the accuracy of our morphometric approach, we calculated for each airway the coefficient of variation of the mean using the formula $(100 \% \times \mathrm{SE} \mathrm{M}) /$ mean. In this formula, SE M relates to the variation between sections within a single airway. The relationships between each airway wall dimension ( $\mathrm{WA}_{\mathrm{i}}, \mathrm{WA}_{\mathrm{bm}}, \mathrm{WA}_{0}, \mathrm{WA}_{\mathrm{t}}, \mathrm{WA}_{\mathrm{m}}, \mathrm{WA}_{\text {cart }}$ $\left.W A_{\text {epi }}, H_{\text {epi }}, F_{\text {epi }}\right)$ and airway size $\left(P_{b m}\right)$ were assessed using linear regression analysis. Previous studies found linear relationships between the square root of airway wall areas and airway size $(1,11,23-25)$. We did a square root transformation on the airway areas of this study, again resulting in normal distributions of data.

We calculated the average specific compliance, specific hysteresis, and collapsibility for the first cycle $\left(\mathrm{sCdyn}_{1}, \mathrm{~s}_{1}, \mathrm{Pcol}_{1}\right)$ and for the average of the second, third, and fourth cycle (sCdyn, sn, sPcol) for all airway segments. Furthermore, we calculated the average specific pressure drop. This was done for each of the three contractile conditions (baseline, methacholine, and isoprenaline). R epeated-measurements analysis of variance (A NOVA) was used to assess the overall differences between the three conditions, followed by pairwise t tests in case the former test was significant. We investigated the correlation

TABLE 1

\section{STUDY POPULATION AND LUNG FUNCTION CHARACTERISTICS}

\begin{tabular}{|c|c|c|c|c|}
\hline & $\begin{array}{l}\text { Patients } \\
\text { (n) }\end{array}$ & Mean & SD & Range \\
\hline Age, yr & 29 & 61 & 11 & $22-73$ \\
\hline Sex, male:female & $20: 9$ & & & \\
\hline Lung or lobe resected, right side & 14 & & & \\
\hline Lung or lobe resected, left side & 15 & & & \\
\hline TLC, \% pred & 18 & 100 & 15 & $67-132$ \\
\hline FRC, \% pred & 9 & 108 & 36 & 74-190 \\
\hline $\mathrm{RV}, \%$ pred & 18 & 138 & 59 & $65-252$ \\
\hline $\mathrm{FEV}_{1}, \%$ pred & 27 & 80 & 17 & $43-106$ \\
\hline FVC, \% pred & 27 & 99 & 17 & $59-135$ \\
\hline $\mathrm{FEV}_{1} / \mathrm{FVC}, \%$ & 27 & 65 & 12 & $41-85$ \\
\hline $\mathrm{FEV}_{1} / \mathrm{FVC} \%$ pred & 27 & 84 & 15 & $55-115$ \\
\hline RV/TLC\% pred & 18 & 129 & 61 & $72-273$ \\
\hline$\dot{V_{m a x}}{ }_{50}, \%$ pred & 11 & 42 & 22 & $11-77$ \\
\hline$\dot{\mathrm{V}} \max _{25}, \%$ pred & 13 & 38 & 22 & $6-83$ \\
\hline$\Delta \mathrm{FEV}_{1} \%$ pred & 23 & 1 & 3 & $-7-6$ \\
\hline$\Delta \mathrm{FEV}_{1} \%$ ini & 23 & 1.6 & 4 & $-8-7$ \\
\hline
\end{tabular}

Definition of abbreviations: $\Delta \mathrm{FEV}_{1} \%$ ini $=$ change of $\mathrm{FEV}_{1}$ after bronchodilatation as a percentage of prebronchodilator $\mathrm{FEV}_{1} ; \Delta \mathrm{FEV}_{1} \%$ pred = change of $\mathrm{FEV}_{1}$ after bronchodilatation as a percentage of predicted $\mathrm{FEV}_{1} ; \mathrm{FEV}_{1} / \mathrm{FVC}=$ forced expiratory volume in one second as percentage of forced vital capacity; $\mathrm{FEV}_{1} / \mathrm{FVC} \%$ pred $=\mathrm{FEV}_{1}$ as a fraction of FVC; RV = residual volume; RV/TLC\% pred = RV as a fraction of TLC; Vmax $_{25}, \%$ pred $=$ maximal flow at $25 \%$ of forced vital capacity; $\dot{V}_{\max }=$ maximal flow at $50 \%$ of forced vital capacity. 
TABLE 2

MECHANICAL PROPERTIES OF AIRWAY SEGMENTS FOR THE FIRST AND CONSECUTIVE CYCLES*

\begin{tabular}{|c|c|c|c|c|}
\hline Condition & $\mathrm{n}$ & $\begin{array}{c}\text { Cycle } 1 \\
\text { Mean } \pm \text { SD (range) }\end{array}$ & $\mathrm{n}$ & $\begin{array}{c}\text { Cycles } 2,3 \text {, and } 4 \text { Average } \\
\text { Mean } \pm \text { SD (range) }\end{array}$ \\
\hline \multicolumn{5}{|c|}{ 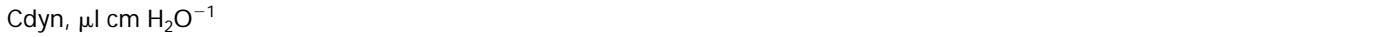 } \\
\hline Baseline & 22 & $1.45 \pm 1.0(0.2$ to 3.8$)$ & 35 & $1.52 \pm 1.0(0.2$ to 3.8$)$ \\
\hline Methacholine & 22 & $1.36 \pm 1.1$ (0.1 to 3.6$)$ & 35 & $1.42 \pm 1.1$ (0.1 to 3.9$)$ \\
\hline Isoprenaline & 33 & $2.43 \pm 1.5(0.1$ to 5.7$)$ & 35 & $2.62 \pm 1.6(0.1$ to 5.9$)$ \\
\hline \multicolumn{5}{|l|}{$\mathrm{sCdyn}, \mathrm{cm} \mathrm{H}_{2} \mathrm{O}^{-1}$} \\
\hline Baseline & 22 & $0.053 \pm 0.02(0.02$ to 0.09$)$ & 35 & $0.059 \pm 0.03(0.01$ to 0.10$)$ \\
\hline Methacholine & 22 & $0.049 \pm 0.03(0.01$ to 0.09$)$ & 35 & $0.052 \pm 0.03(0.01$ to 0.09$)$ \\
\hline Isoprenaline & 33 & $0.080 \pm 0.03(0.01$ to 0.15$)$ & 35 & $0.085 \pm 0.03(0.01$ to 0.15$)$ \\
\hline \multicolumn{5}{|l|}{$\eta, \mu \mathrm{l} \mathrm{cm} \mathrm{H}_{2} \mathrm{O}$} \\
\hline Baseline & 18 & $75.9 \pm 71$ (4 to 261$)$ & 24 & $55.9 \pm 54$ ( 1 to 187$)$ \\
\hline Methacholine & 18 & $70.1 \pm 81$ ( 6 to 267$)$ & 24 & $43.5 \pm 45$ ( 3 to 223 ) \\
\hline Isoprenaline & 25 & $63.2 \pm 88$ (4 to 268$)$ & 26 & $48.1 \pm 39$ ( 3 to 138$)$ \\
\hline \multicolumn{5}{|l|}{$s \eta, \%$} \\
\hline Baseline & 18 & $19.8 \pm 9$ (4 to 34$)$ & 24 & $13.5 \pm 7$ (1 to 39$)$ \\
\hline Methacholine & 18 & $18.0 \pm 11(4$ to 43$)$ & 24 & $12.9 \pm 8(2$ to 35$)$ \\
\hline Isoprenaline & 25 & $11.2 \pm 6$ ( 2 to 28$)$ & 26 & $7.1 \pm 4$ ( 1 to 16$)$ \\
\hline \multicolumn{5}{|l|}{ Pcol, $\mathrm{cm} \mathrm{H}_{2} \mathrm{O}$} \\
\hline Baseline & 35 & $-4.0 \pm 5(-16$ to 1$)$ & 35 & $-3.4 \pm 5(-17$ to 1$)$ \\
\hline Methacholine & 35 & $-4.0 \pm 5(-16$ to 1$)$ & 35 & $-3.5 \pm 4(-16$ to 1$)$ \\
\hline Isoprenaline & 35 & $-2.1 \pm 3(-11$ to 1$)$ & 35 & $-1.9 \pm 2.6(-11$ to 1$)$ \\
\hline
\end{tabular}

* Mechanical properties of isolated airway segments at baseline, after contraction with methacholine, and after relaxation with isoprenaline. The mechanical properties examined are compliance Cdyn, hysteresis $\eta$, and collapsibility Pcol. Compliance was normalized for airway volume (sCdyn) and hysteresis for the maximal possible hysteresis ( $(n)$. The values for the first cycle and for the average of the consecutive cycles are shown separately because the mechanical properties of the first cycle were different from that of consecutive cycles.

between the mechanical properties of the second, third, and fourth cycle (sC dyn, $\left.s \eta, P_{c o l}\right)$ with airway wall dimensions ( $W A_{b m}, W A_{0}, W A_{t}$, $W A_{m}, W A_{c a r t}, W A_{e p i}, F_{\text {epi }}$ ) using Spearman's correlation coefficient ( $r)$. When a mechanical property correlated to various airway wall dimensions in univariate analysis, we studied their simultaneous effects using multiple regression analysis. D ata are expressed as mean \pm standard deviation and range, unless indicated otherwise. $\mathrm{p} V$ alues given are two-sided. In view of the multiple comparisons, $p$ values between 0.05 and 0.01 are considered as indicative only.

\section{RESULTS}

\section{Study Population and Lung Function}

L ung function and patient characteristics of the patients with COPD are shown in Table 1. Out of the group of 27 COPD patients with preoperative lung function test results, eight patients had no significant reduction of maximal expiratory airflow ( $\left.F E V_{1} / F V C>70 \%\right), 12$ patients had a mild reduction of maximal expiratory airflow (FEV 1 /FV C 60 to $70 \%$ ), and seven patients had a more severe reduction ( $F E V{ }_{1} / F V C<60 \%$ predicted). Increased residual volume [R $\mathrm{R}>\mathrm{RV}$ (pred) + 2SD ] was present in five of the 18 patients who had body plethysmography. Reversibility of bronchial obstruction defined as $\Delta \mathrm{FEV}_{1} \%$ pred $>15 \%$ and $\Delta \mathrm{FEV}_{1} \%$ ini $>15 \%$ was not present in any of the 23 patients.

\section{Airway Segments}

W e successfully completed all measurements of 35 cannulated watertight airway segments. The diameter of the cannulas used was $1.3 \pm 0.39$ ( 1 to 2 ) $\mathrm{mm}$; the length of the stretched airways was $14.2 \pm 4.2$ ( 6.7 to 21.2 ) $\mathrm{mm}$. The median of the estimated volume of the segments was 30.7 (5.3 to 66.6) $\mu$ l. Cycling frequency was $3.1 \pm 1.9,5 \pm 5.4$, and $1.8 \pm 0.9$ cycles $\mathrm{min}^{-1}$ for baseline, methacholine, and isoprenaline, respectively. A t baseline, after methacholine and isoprenaline, 13, 13, and 2 out of the cycles, respectively, started above $0 \mathrm{~cm} \mathrm{H}_{2} \mathrm{O}$ and were therefore excluded for analysis.

\section{Compliance, Hysteresis, and Collapsibility}

The values for compliance and specific compliance ( $C$ dyn and $s C$ dyn), hysteresis and specific hysteresis ( $\eta$ and $s \eta$ ), and collapsibility (Pcol) at baseline, after methacholine, and after isoprenaline are shown in Table 2 and in Figure 4.

On average, the specific compliance of the first cycle $\left(\mathrm{sCdyn}_{1}\right)$ was 13,11 , and $8 \%$ below the mean $\mathrm{sC}$ dyn of the subsequent cycles for baseline $(p<0.001)$, methacholine $(p=$ $0.03)$, and isoprenaline ( $<<0.001)$, respectively (Figure 4$)$. The mean sC dyn after methacholine was $0.009 \mathrm{~cm} \mathrm{H}_{2} \mathrm{O}^{-1}$ below that of baseline $(p=0.04)$. sC dyn after isoprenaline was $0.033 \mathrm{~cm} \mathrm{H} \mathrm{O}^{-1}$ higher compared with baseline $(p<0.001)$ and $0.042 \mathrm{~cm} \mathrm{H}_{2} \mathrm{O}^{-1}$ higher compared with methacholine $(\mathrm{p}<$ 0.001). Expressed as percentages, these differences were 4 , 101 , and $197 \%$, respectively.

The mean specific hysteresis of the first cycle was 34, 30, and $37 \%$ higher compared with $s \eta$ of the subsequent cycles for baseline, methacholine, and isoprenaline, respectively ( $p<$ 0.001 ) (Figure 4). The mean s $n$ after methacholine was not significantly different from baseline. sn after isoprenaline was $6.8 \%$ lower compared with baseline $(p<0.001)$ and $7 \%$ lower compared with methacholine $(p<0.001)$. Expressed as percentages, these differences were 9 and $39 \%$, respectively.

The mean pressure drop within the 2 min after the last inflation of the compliance measurement was 6.5, 7.1, and 7.2 $\mathrm{cm} \mathrm{H}_{2} \mathrm{O}$ for baseline, methacholine, and isoprenaline, respectively. The mean specific pressure drop for these conditions was $0.009,0.001$, and $0.001 \mathrm{~cm} \mathrm{H}_{2} \mathrm{O} \mathrm{mm} \mathrm{mm}^{-2}$. The differences between the three conditions were not significant.

The collapsibility of the first cycle was $0.6,0.5$, and $0.2 \mathrm{~cm}$ $\mathrm{H}_{2} \mathrm{O}$ below Pcol of the next cycles for baseline, methacholine, and isoprenaline, respectively (all $p<0.001$ ) (Figure 4). Pcol after isoprenaline was 1.5 and $1.6 \mathrm{~cm} \mathrm{H}_{2} \mathrm{O}$ above the values at baseline and with methacholine, respectively (both $p<0.001$ ). Collapsibility at baseline and after methacholine were not significantly different. A fter maximal contraction, there were five airways that collapsed at pressures of $0 \mathrm{~cm} \mathrm{H}{ }_{2} \mathrm{O}$ or higher. 

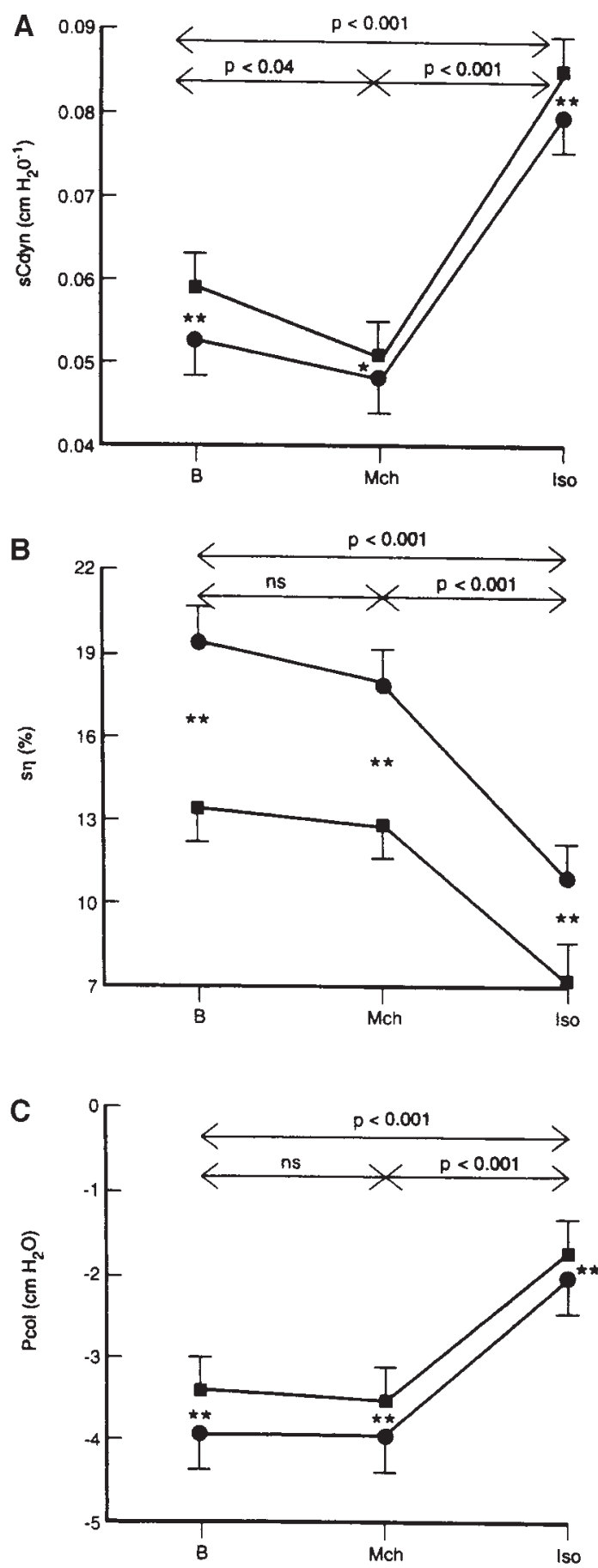

Figure 4. Dynamic properties of isolated airway segments at baseline, after methacholine, and after isoprenaline. (A) Specific compliance (sCdyn). (B) Specific hysteresis (sๆ). (C) Collapsibility Pcol. The error bars represent the SEM. Closed circles represent the first cycles, closed squares the average of the second, third, and fourth cycle. Arrows denote comparisons between squares. $\mathrm{B}=$ baseline; $\mathrm{MCh}=$ methacholine $\left(10^{-4} \mathrm{M}\right)$; Iso $=$ isoprenaline $\left(10^{-4} \mathrm{M}\right){ }^{*} \mathrm{p}=$ $0.03 ; *$; $<0.001$.

A fter maximal relaxation, this number increased to nine. Pcol and $\mathrm{sC}$ dyn after methacholine were significantly correlated $(r=$ $0.54, p=0.001$ ). In other words, the stiffer the airway after methacholine, the less collapsible it was.

The median fluid volume displaced by methacholine-induced constriction was $-9.4(-41$ to 10$) \mu$ l or $-37(-103$ to 119$) \%$
TABLE 3

DIMENSIONS OF ISOLATED AIRWAY SEGMENTS

\begin{tabular}{|c|c|}
\hline Airway Dimensions & Mean $\pm \mathrm{SD}$ (range) \\
\hline Internal perimeter, $\mathrm{mm}$ & $6.1 \pm 1.2(4.1-8.4)$ \\
\hline Airway wall thickness, $\mathrm{mm}$ & $0.3 \pm 0.1(0.11-0.61)$ \\
\hline Length of airway segment, $\mathrm{mm}$ & $14.2 \pm 4.2(6.7-21.2)$ \\
\hline \multicolumn{2}{|l|}{$\begin{array}{l}\text { Equations of airway dimensions (in } \mathrm{mm} \text { ) } \\
\text { as a function of airway size }\end{array}$} \\
\hline Wall area basement membrane, $W^{b m}$ & $\sqrt{ } \mathrm{WA}_{\mathrm{bm}}=0.19+0.071 \mathrm{P}_{\mathrm{bm}}$ \\
\hline Outer wall area, $W_{0}$ & $\sqrt{ } W_{A_{o}}=-0.15+0.206 P_{b m}$ \\
\hline Total wall area, $\mathrm{WA}_{\text {tot }}$ & $\sqrt{ } W_{A}=-0.06+0.226 P_{b m}$ \\
\hline Smooth muscle area, $W_{m}$ & $\sqrt{ } W_{A_{m}}=0.04+0.034 P_{b m}$ \\
\hline Cartilage area, $\mathrm{WA}_{\text {cart }}$ & $\sqrt{ } \mathrm{WA}_{\text {cart }}=-0.18+0.067 \mathrm{P}_{\mathrm{bm}}$ \\
\hline Epithelial area, $W_{\text {epi }}$ & $\sqrt{ } \mathrm{WA}_{\mathrm{epi}}=-0.01+0.042 \mathrm{P}_{\mathrm{bm}}$ \\
\hline
\end{tabular}

of the estimated airway volume. For the relaxing airway after isoprenaline these values were $5.9(-7$ to 46$) \mu$ l or $31.4(-14$ to 58) $\%$.

\section{Airway Dimensions}

The intra- and interobserver variability were well below $10 \%$ and $15 \%$, respectively, for each of the airway wall dimensions. There was no systematic relationship between airway size $\left(\mathrm{P}_{\mathrm{bm}}\right)$ and the intra- or interobserver variability for any variable. The mean coefficients of variation of the individual means for the airway dimensions for $P_{b m}, W A_{b m}, W A_{0}, W A_{t}$, $W A_{m}, W A_{\text {cart }}, H_{\text {epi }}$, and $F_{\text {epi }}$ were $4,6,8,8,10,33,12$, and $13 \%$, respectively. Characteristics of the airways are shown in Table 3. Highly significant $(p<0.002)$ linear relations were found between the square root of all airway wall areas and $\mathrm{P}_{\mathrm{bm}}$. There was a positive correlation between $\mathrm{H}_{\text {epi }}$ and $\mathrm{P}_{\mathrm{bm}}(\mathrm{r}=$ $0.43, p=0.02$ ); in other words, the epithelial layer in large airways was higher compared with small airways. Furthermore, there was a positive correlation between $F_{e p i}$ and $P_{b m}(r=$ $0.39, p=0.04$ ), meaning there was more loss of epithelium in smaller airways. The average $\mathrm{H}_{\mathrm{epi}}$ was $10.7 \pm 6.3$ (0.1 to 28.7) $\mu \mathrm{m}$ and $F_{\text {epi }}$ was $53 \pm 24$ ( 1 to 96 ) \%. The membranous airways disease score was $119 \pm 40$ ( 38 to 223).

\section{Lung Function versus Compliance, Hysteresis, and Collapsibility}

Specific hysteresis at baseline correlated to $\mathrm{FEV}_{1} / \mathrm{FV} \mathrm{C}(r=$ $-0.57, p=0.06)$ and $R V / T L C \%$ pred $(r=0.5, p=0.05)$. H ysteresis after methacholine correlated to $\mathrm{FEV}_{1} / \mathrm{FVC}(\mathrm{r}=$ $-0.68, p=0.02), R \vee(r=0.5, p=0.05)$, and $R \vee / T L C \%$ pred $(r=0.67, p=0.007)$. There was no correlation between hysteresis and parameters of reversibility $\left(\Delta \mathrm{FEV} \mathrm{V}_{1} \%\right.$ pred and $\Delta \mathrm{FEV}_{1} \%$ ini). Specific compliance and collapsibility did not correlate to the parameters as mentioned previously.

\section{Airway Dimensions versus Compliance, Hysteresis, and Collapsibility}

Specific compliance ( $s C$ dyn) at baseline, after methacholine, and after isoprenaline was independent of airway size ( $p=$ 0.2 ). Specific compliance at baseline correlated significantly to the total wall area $\left(W A_{t}\right)(r=-0.35, p=0.04)$ and outer wall area $\left(W A_{0}\right)(r=-0.39, p=0.02)$, not to other airway wall areas. B ecause the $W A_{t}$ components $W A_{\text {epi }}$ and $W A_{b m}$ did not correlate to sCdyn, we conclude that of all factors studied $\mathrm{WA}_{\mathrm{o}}$ is the most important component for sC dyn at baseline, accounting for $15 \%$ of the variability. A fter methacholine, sC dyn correlated negatively to the amount of smooth muscle $\left(W A_{m}\right)(r=-0.37, p=0.05)$ and to the area of epithelium (W $\left.A_{\text {epi }}\right)(r=-0.37, p=0.05)$. B ecause of the strong correla- 
tions of WA $\mathrm{A}_{m}$ and $W \mathrm{~A}_{\mathrm{epi}}$, no conclusion about which of the two variables was more predictive for $\mathrm{sC}$ dyn could be obtained using multiple regression analysis. Specific compliance after isoprenaline did not correlate to any of the airway dimensions. The difference between $\mathrm{SC}$ dyn after isoprenaline and methacholine correlated significantly to $\mathrm{WA}_{\mathrm{m}}(\mathrm{r}=0.45$, $\mathrm{p}=0.02$ ) but not to $W A_{\text {epi }}$. The difference between $s C d y n_{1}$ and $\mathrm{SC}$ dyn at baseline, after methacholine, and isoprenaline did not correlate to any airway wall dimension.

Specific hysteresis $(\mathrm{s} \eta)$ at baseline was positively correlated to $W_{t}(r=0.41, p=0.04)$ and to $W A_{m}(r=0.44, p=0.04)$, but not to other airway wall dimensions $\left(W A_{b m}, W A_{\text {cart }}\right.$, $\left.W A_{\text {epi }}\right)$. B ecause $W A_{t}$ and $W A_{m}$ were significantly correlated, it was not possible to differentiate whether $W A_{t}$ or $W A_{m}$ was the most predictive dimension for $s_{\eta}$ in a multiple regression model. Specific hysteresis after methacholine correlated to $W_{t}(r=0.54, p=0.006), W A_{0}(r=0.52, p=0.01)$, and $W A_{m}(r=0.6, p=0.004)$, and to $W A_{\text {cart }}(r=0.42, p=0.04)$. Multiple regression analysis showed that $\mathrm{WA}_{m}$ was the only remaining significant predictive dimension $(p=0.01)$. Specific hysteresis after isoprenaline did not correlate to any of the airway dimensions. The difference between $s \eta_{1}$ and $s \eta$ at baseline, after methacholine, and after isoprenaline did not correlate to any airway wall dimension.

The specific pressure drop after the fourth inflation, indicating hysteresis and leak, was correlated negatively to all airway dimensions for baseline, after methacholine, and after isoprenaline $(p<0.01)$. Multiple regression analysis showed that at baseline, WA epi was the only remaining significant predictive dimension for the pressure drop. A fter methacholine, $W A_{0}$ was the only significant dimension $(p=0.04)$ determining the pressure drop. A fter isoprenaline, multiple regression analysis showed that WA。 and WA epi were both predictive. Because of the strong correlations between the two, no conclusion about which variable was most predictive could be obtained. Thus, small airways with thinner epithelium and smaller outer airway wall area had a faster pressure drop after the final inflation.

Pcol of the airways at baseline, after methacholine, and after isoprenaline did not correlate to any of the airway wall dimensions ( $\left.\mathrm{WA}_{\mathrm{bm}}, \mathrm{WA}_{\mathrm{o}}, \mathrm{WA}_{\mathrm{t}}, \mathrm{WA}_{\mathrm{m}}, \mathrm{WA}_{\text {cart }} \mathrm{WA}_{\text {epi }}\right)$.

\section{DISCUSSION}

Chronic inflammation of the airways results in fibrous tissue deposition and thickening of the airway wall. We thought it likely that this remodeling makes the airway less compliant. 0 ur results show that of the airway dimensions studied the bronchial smooth muscle area, not total wall area, is the most important determinant for airway compliance, hysteresis, and collapsibility.

\section{Compliance}

A irway compliance is an important predictor of airway diameter and lung compliance $(26,27)$. We expected that the inner and outer wall area of airways from smokers with varying degrees of airflow obstruction would be important determinants of sCdyn for a number of reasons. The inner and outer wall area correlated positively to inflammatory changes within the airway wall in smokers $(1,11)$. Furthermore, chronic airway inflammation is related to an increased amount of fibrous tissue within the airway wall $(10,11,23)$ which is likely to make the airway stiffer. Though $\mathrm{sC}$ dyn correlated to the outer airway wall area at baseline tone, no correlation was present between the outer and inner wall area and $\mathrm{sC}$ dyn after maximal relaxation of bronchial smooth muscle tone. A fter maxi- mal contraction of the smooth muscle, sCdyn decreased and smooth muscle area was the most important airway dimension for $\mathrm{SC}$ dyn. We believe that the weak correlation between $W A_{m}$ and $s C$ dyn may well underestimate the importance of smooth muscle for airway compliance. O ur measurement of $W_{\mathrm{m}}$ included not only smooth muscle cells but also connective tissue within the smooth muscle bundles, which increases the variability of the $W A_{m}$ measurement. Furthermore $W A_{m}$ is likely to be a poor estimate of the stress that can be generated by the smooth muscle as this is also dependent on the orientation of the muscle bundles in the airway wall, which was not assessed in our study. How can we explain that the inner and outer wall area did not correlate to $\mathrm{sC}$ dyn? It could be that the airways we investigated were not thickened by chronic inflammation. We think this is unlikely because the selection criteria for patients and lung tissue were the same as for previous studies $(1,11,23-25)$. Furthermore, we investigated small airways, where inflammatory changes are known to be most severe (1). Finally, inflammation scores were within the same range as in a previous study (1) and these scores are known to correlate positively to the inner and outer airway wall area. The lack of correlation between inner and outer wall area and $\mathrm{sC}$ dyn could also be explained by assuming that these areas correlate poorly to the presence of structural components important for $\mathrm{SC}$ dyn such as collagen.

Specific compliance at baseline was two-thirds of $\mathrm{sC}$ dyn of the maximally relaxed airway. The initially high intrinsic contractile state could partly be an artifact related to our tissue preparation. Loss of epithelium was present in many of the airways we studied. Epithelium is a well-known source of bronchodilating substances (28) and its loss might therefore have increased smooth muscle tone. H owever, sC dyn at baseline did not correlate significantly to the percentage of the basement membrane covered by epithelium. Furthermore, sC dyn at baseline in our study was only slightly higher than other in vivo studies of human airways, taking into account differences in methodology (29-32). If there is a high smooth muscle tone in vivo too, then it is puzzling why none of the patients in our study and only one of 58 patients in a previous study showed reversibility after bronchodilatation (1). How can this discrepancy be explained? In our experimental setup airways were inflated by a mechanical pump. In vivo, airways are dilated by tethering forces of alveolar attachments in relation to breathing cycles. We speculate that in lungs of patients with COPD loss of alveolar attachments results in absence or incomplete dilation of segments or complete membranous airways, even after adequate relaxation of bronchial smooth muscle.

\section{Hysteresis}

Smooth muscle tone is known to be an important contributor to hysteresis $(33,34)$. We found a significant decrease of $\mathrm{s} \eta$ with maximal relaxation compared with baseline and with the maximally contracted airways. H owever, we did not find a difference between $s \eta$ at baseline and after maximal contraction of the smooth muscle. This can be explained by the smaller increase in volume necessary to inflate a contracted airway to the pressure limit of $15 \mathrm{~cm} \mathrm{H} O$. Surprisingly, a substantial portion of the $s \eta$ was not contributed by smooth muscle tone. A fter maximal relaxation, mean $\mathrm{s} \eta$ was still $53 \%$ of baseline $\mathrm{S \eta}$. $\mathrm{H}$ ysteresis of lung tissue is related to four different mechanisms: kinetics of cross-bridge attachment-detachment, kinetics related to the surface film, kinetics of fiber-fiber networking within the connective tissue matrix, and the kinetics of recruitment-derecruitment (35). For the sn of fluid-filled relaxed airway segments in our study kinetics of cross-bridge at- 
tachment-detachment, surface tension, and recruitment do not play an important role. Therefore, it is likely that sn of relaxed airway segments originates within the connective tissue matrix of the airway wall.

A t baseline, $\mathrm{s \eta}$ was correlated both to the smooth muscle area and to total airway wall area. A fter maximal contraction of the smooth muscle, its area was the single most important airway wall dimension related to $\mathrm{s} \eta$. A fter maximal relaxation, the total wall area was not correlated to $\mathrm{s} \eta$. These findings suggest that the total wall area does not reflect changes in the fibrous tissue composition which determines sn. A surprising finding was that specific hysteresis at baseline and after methacholine correlated to in vivo lung function parameters of airflow obstruction. If not a false-positive finding, this might reflect the role of smooth muscle tone in the pathogenesis of airflow obstruction in COPD.

\section{Collapsibility}

To our knowledge, this is the first study on the relation between collapsibility and airway dimensions of human small airways. Collapsibility was correlated to smooth muscle tone and not to any of the airway dimensions. R eduction of smooth muscle tone made the airway more compliant and more collapsible. A irways with the biggest change in compliance between the maximally contracted and maximally relaxed state also had the biggest change in collapsibility. $\mathrm{M}$ any airways collapsed at negative pressures close to $0 \mathrm{~cm} \mathrm{H}_{2} \mathrm{O}$ or higher. In vivo these airways will depend on parenchymal recoil pressure to remain open. The use of bronchodilators in patients might therefore facilitate airway closure during expiration. The importance of smooth muscle tone for the collapsibility of large airways has been reported for different animal species (3639). We conclude that collapsibility of small airways will to an important degree depend on smooth muscle tone and parenchymal support.

\section{Effects of Volume History}

The mechanical characteristics of the first cycle were substantially different from the subsequent cycles. O n the first cycle, airways were less compliant, had a greater hysteresis, and were less collapsible compared with subsequent cycles. Similar findings were obtained earlier in bronchi and tracheal strip preparations from dogs $(33,40)$. In vivo, the effect of volume history on compliance and hysteresis has been described for normal subjects, asthmatics, and patients with CO PD (41-44). In the general population and in COPD patients a deep inhalation results in bronchodilatation $(41,44)$. In asthmatics deep inhalation can result in bronchoconstriction or bronchodilatation. In COPD, this effect is reduced but still present after inhalation of bronchodilators (44). We found that the difference in $\mathrm{sC}$ dyn and $\mathrm{s} \eta$ between the first and the subsequent cycles persisted even after maximal relaxation by isoprenaline. We therefore conclude that the effect of volume history on sC dyn and $s \eta$ is not only related to smooth muscle tone but also to connective tissue within the airway wall.

\section{Conclusions}

In this study smooth muscle area and tone, but not total wall area, were the most important morphological correlates for the dynamic properties of isolated airways from smokers. We showed that maximal bronchodilatation doubled compliance, reduced hysteresis, and increased collapsibility of airway segments independently of airway wall thickness. The volume history of the isolated airway segments had a substantial effect on compliance, hysteresis, and collapsibility even in the absence of smooth muscle tone.
It was striking that isolated airways showed considerable reversibility of bronchoconstriction whereas in vivo patients with CO PD have very little reversibility of airflow obstruction after inhalation of bronchodilators $(1,45)$. We speculate that in patients with COPD loss of alveolar attachments is responsible for absence or incomplete dilatation of segments of membranous airways, even after effective relaxation of bronchial smooth muscle.

Acknowledgment: The authors thank Alex Nigg for technical advice concerning morphometry, Julius de Vries for the development of the multichannel registration program and data analysis tools. We are indebted to the chest physicians, thoracic surgeons, and pathologists of the Academical Hospital Leiden, Leyenburg Hospital The Hague, Zuider Hospital, and Academical Hospital Rotterdam for their help in obtaining lung tissue specimens and lung function data.

\section{References}

1. Tiddens, H. A. W. M., P. D. Paré, J . C. Hogg, W . C. J . H op, R . L ambert, and J. C. de J ongste. 1995. Cartilaginous airway dimensions and airflow obstruction in human lungs. A m. J. Respir. Crit. Care M ed. 152: 260-266.

2. B ai, T. R. 1990. A bnormalities in airway smooth muscle in fatal asthma. A m. Rev. Respir. D is. 141:552-557.

3. Carroll, N., J. Elliot, A. M orton, and A. James. 1993. The structure of large and small airways in nonfatal and fatal asthma. A m. Rev. Respir. Dis. 147:405-410.

4. James, A . L., P. D. Paré, and J . C. Hogg. 1989. The mechanics of airway narrowing in asthma. A m. Rev. Respir. D is. 139:242-246.

5. L ambert, R. K., B. R. W iggs, and K. K uwano. 1993. Functional significance of increased airway smooth muscle in asthma and COPD. J. A ppl. Physiol. 74:2771-2781.

6. de J ongste, J. C., H. M ons, R. B lock, I. L. Bonta, A. P. Fredriksz, and K. F. Kerrebijn. 1987. Increased in vitro histamine responses in human small airway smooth muscle from patients with chronic obstructive pulmonary disease. A m. Rev. R espir. D is. 135:549-553.

7. Black, J. L. 1991. Pharmacology of airway smooth muscle in chronic obstructive pulmonary disease and in asthma [published erratum appears in A m. Rev. Respir. D is. 1991 144(3, Pt. 1):733]. A m. Rev. Respir. D is. 143:1177-1181.

8. de J ongste, J. C., H. M ons, I. L. B onta, and K. F. Kerrebijn. 1989. R elaxation responses of airway smooth muscle from subjects with and without chronic bronchitis and airflow limitation. Pulm. Pharmacol. 2:75-79.

9. M ullen, J . B., J . L. W right, B . R . W iggs, P. D. Paré, and J . C. H ogg. 1985. R eassessment of inflammation of airways in chronic bronchitis. $\mathrm{Br}$. M ed. J. 291:1235-1239.

10. R oche, W. R., R. B easley, J. H. Williams, and S. T. H olgate. 1989. Subepithelial fibrosis in the bronchi of asthmatics. L ancet 1:520-524.

11. Bosken, C. H., B. R. Wiggs, P. D. Paré, and J. C. Hogg. 1990. Small airway dimensions in smokers with obstruction to airflow. Am. Rev. Respir. D is. 142:563-570.

12. B rewster, C. E., P. H. H owarth, R. D jukanovic, J. Wilson, S. T. H olgate, and W. R. Roche. 1990. M yofibroblasts and subepithelial fibrosis in bronchial asthma. A m. J. Respir. Cell M ol. Biol. 3:507-511.

13. Wilson, J. W., and X. Li. 1997. The measurement of reticular basement membrane and submucosal collagen in the asthmatic airway. Clin. Exp. Allergy 27:363-371.

14. A merican Thoracic Society. 1987. Standards for the diagnosis and care of patients with chronic obstructive pulmonary disease (COPD) and asthma. A m. Rev. Respir. D is. 136:225-243.

15. Q uanjer, P. H., A . D alhuijsen, and B . C . Z omeren. 1983. Summary equations of reference values. Bull. E urop. Physiopath. Resp. 19:45-51.

16. Hughes, J. M., F. G. H oppin, J r., and J. M ead. 1972. E ffect of lung inflation on bronchial length and diameter in excised lungs. J. A ppl. Physiol. 32:25-35.

17. Hughes, J. M., H. A . J ones, and A . G. W ilson. 1975. B ronchial hysteresis in excised lungs. J. Physiol. 249:435-443.

18. Karlinsky, J. B., G. L. Snider, C. Franzblau, P. J. Stone, and F. G. H oppin, J r. 1976. In vitro effects of elastase and collagenase on mechanical properties of hamster lungs. A m. Rev. Respir. D is. 113:769-777.

19. Wilson, J. W., X. Li, and M. C. Pain. 1993. The lack of distensibility of asthmatic airways. A m. Rev. Respir. D is. 148:806-809.

20. B ai, A ., D. H. E idelman, J. C. Hogg, A . L. James, R. K. L ambert, M. S. Ludwig, J. Martin, D. M. McD onald, W. A. M itzner, M. O kazawa, R. J . Pack, P. D. Paré, R. R. Schellenberg, H. A. W . M. Tiddens, E. M . 
W agner, and D. Y ager. 1994. Proposed nomenclature for quantifying subdivisions of the bronchial wall. J. A ppl. Physiol. 77:1011-1014.

21. Wright, J. L., M. Cosio, B. Wiggs, and J. C. Hogg. 1985. A morphologic grading scheme for membranous and respiratory bronchioles. A rch. Pathol. L ab. M ed. 109:163-165.

22. Bland, J. M., and D. G. A Itman. 1986. Statistical methods for assessing agreement between two methods of clinical measurement. $L$ ancet 1:307310.

23. Kuwano, K., C. H. B osken, P. D. Paré, T. R. B ai, B. R. Wiggs, and J. C. Hogg. 1993. Small airways dimensions in asthma and chronic obstructive pulmonary disease. A m. Rev. Respir. Dis. 148:1220-1225.

24. Tiddens, H. A. W. M., J. M. Bogaard, J. C. de J ongste, W. C. J. H op H. O. Coxson, and P. D. Paré. 1996. Physiological and morphological determinants of maximal expiratory flow in chronic obstructive lung disease. E ur. Respir. J. 9:1785-1794.

25. Tiddens, H. A. W. M., L. P. K oopman, R. K. Lambert, W. M. Elliott, W. C. J. H op, T. W. van den M ark, W. J. de B oer, and J. C. de J ongste. 1997. A irway wall dimensions and bronchial responsiveness in cystic fibrosis lungs. E rasmus U niversity, R otterdam, The $\mathrm{N}$ etherlands.

26. Clay, T. P., J. M. Hughes, and H. A . Jones. 1977. R elationship between intrapulmonary airway diameter and smooth muscle tone in excised lungs. J. Physiol. 273:355-365.

27. M itzner, W., S. B losser, D. Y ager, and E. W agner. 1992. E ffect of bronchial smooth muscle contraction on lung compliance. J. A ppl. Physiol. 72:158-167.

28. Hulsmann, A . R ., and J. C. D e J ongste. 1996. M odulation of airway responsiveness by the airway epithelium in humans, putative mechanisms. Clin. Exp. Allergy 26:1236-1242.

29. Tisi, G. M., V. D. M inh, and P. J. Friedman. 1975. In vivo dimensional response of airways of different size to transpulmonary pressure. J. A ppl. Physiol. 39:23-29.

30. Prakash, U. B., and R. E. H yatt. 1978. Static mechanical properties of bronchi in normal excised human lungs. J. A ppl. Physiol. 45:45-50.

31. Hahn, H. L., A. Watson, A. G. Wilson, and N. B. Pride. 1980. Influence of bronchomotor tone on airway dimensions and resistance in excised dog lungs. J. A ppl. Physiol. 49:270-278.

32. B aier, H., S. Z arzecki, and A . W anner. 1981. Influence of lung inflation on the cross-sectional area of central airways in normals and in patients with lung disease. Respiration 41:145-154.

33. Sasaki, H., and F. G. H oppin, J r. 1979. H ysteresis of contracted airway smooth muscle. J. A ppl. Physiol. 47:1251-1262.

34. Wang, Y. T., L. M. Thompson, E. P. Ingenito, and R. H. Ingram, J r. 1990. E ffects of increasing doses of beta-agonists on airway and parenchymal hysteresis. J. A ppl. P hysiol. 68:363-368.

35. Fredberg, J. J., and D. Stamenovic. 1989. On the imperfect elasticity of lung tissue. J. A ppl. Physiol. 67:2408-2419.

36. Olsen, C. R., A . E. Stevens, and M . B. M cllroy. 1967. R igidity of trachea and bronchi during muscular constriction. J. A ppl. Physiol. 23:27-43.

37. Penn, R. B., M. R. Wolfson, and T. H. Shaffer. 1988. E ffect of tracheal smooth muscle tone on collapsibility of immature airways. J. A ppl. Physiol. 65:863-869.

38. O kazawa, M ., and P. D. Paré. 1994. Pressure area relationship of membranous airways in rabbit (abstract). A m. J. Respir. Crit. Care M ed. 149: A 770.

39. M cF awn, P. K ., and H. W. M itchell. 1997. B ronchial compliance and wall structure during development of the immature human and pig lung. Eur. Respir. J. 10:27-34.

40. G unst, S. J. 1983. Contractile force of canine airway smooth muscle during cyclical length changes. J. A ppl. P hysiol. 55:759-769.

41. Sparrow, D., G. T. O 'Connor, S. T. Weiss, D. D eM olles, and R. H. Ingram, J r. 1997. Volume history effects and airway responsiveness in middle-aged and older men: the N ormative A ging Study. A m. J. R espir. Crit. Care M ed. 155:888-892.

42. Wheatley, J. R., P. D. Paré, and L. A . Engel. 1989. R eversibility of induced bronchoconstriction by deep inspiration in asthmatic and normal subjects. E ur. Respir. J. 2:331-339.

43. Lim, T. K., N. B. Pride, and R. H. Ingram, Jr. 1987. E ffects of volume history during spontaneous and acutely induced air-flow obstruction in asthma. A m. Rev. Respir. Dis. 135:591-596.

44. Fairshter, R . D. 1985. A irway hysteresis in normal subjects and individuals with chronic airflow obstruction. J. A ppl. Physiol. 58:1505-1510.

45. Riess, A ., B. Wiggs, L. V erburgt, J. L. Wright, J. C. Hogg, and P. D. Paré. 1996. Morphologic determinants of airway responsiveness in chronic smokers. A m. J. Respir. Crit. Care M ed. 154:1444-1449. 